\section{Financiamento de Longo Prazo: Explorando o
Avanço Recente do Mercado de Debêntures
Brasileiro \\ Financiamento de Longo Prazo: Explorando o
Avanço Recente do Mercado de Debêntures
Brasileiro Brasileiro} Long-term Financing: Exploring the Recent Advances in the Brazilian Bond Market

\author{
Lucas Boareto da Aparecida ${ }^{\circ}$ \\ Sergio Giovanetti Lazzarini' $\odot$ \\ Adriana Bruscato Bortoluzzo*1 1
}

\section{RESUMO}

Contexto: houve no Brasil uma expansão de captaçóes privadas via debêntures, especialmente a partir de 2017. Antes disso, as fontes de financiamento de longo prazo se concentravam na captação via recursos estatais. Objetivo: o estudo examina as possíveis razões dessa expansão e como ela poderia sugerir uma nova tendência de financiar uma maior parcela de projetos de infraestrutura com capital privado. Métodos: por meio de uma abordagem de pesquisa mista, envolvendo testes econométricos de quebra estrutural em séries temporais e análises qualitativas de entrevistas com profissionais do mercado financeiro. Resultados: foi confirmado que houve uma mudança na tendência de emissão de debêntures a partir de 2017, mais pronunciada em alguns setores específicos, como o elétrico. Utilizando entrevistas, sugerimos que os fatores determinantes estão relacionados ao crescimento da demanda por esses títulos de dívida e à redução nas taxas de juros no Brasil. Conclusóes: assim, o estudo reforça a ideia da importância das condiçóes do mercado local e das políticas governamentais e seu efeito na atratividade relativa entre o capital privado e o capital público no financiamento corporativo.

Palavras-chave: financiamento de longo prazo; infraestrutura; debêntures; financiamento público.

\section{ABSTRACT}

Context: in Brazil, there was an expansion of private funding via bond issuances, especially since 2017. Before that period, the sources of longterm financing were concentrated on public funding. Objective: this study aims to explore the main factors that could have positively affect Brazilian bond market and if it would be possible to improve project financing through this debt instruments. Methods: using mixed methods with econometric tests and qualitative interview analysis, this study assesses which were the factors that supported this growth and if there is any difference across industries. Results: we found that a change in the market trend has indeed happened around 2017, and it was more pronounced in specific industries such as electricity. Interviewees suggested that increases in demand (possibly triggered by the reduction of public sources of funding and the fall in local interest rates) could be the main factors that supported this change in trend. Conclusions: therefore, this study reinforces the importance of local market conditions and government policies affecting the relative attractiveness of private versus public sources of corporate investment.

Keywords: long-term financing; bond market; state participation; private sector participation.

\footnotetext{
* Autora Correspondente.

1. Instituto de Ensino e Pesquisa (INSPER), São Paulo, SP, Brasil.
}

Como citar: Aparecida, L. B. da., Lazzarini, S. G., \& Bortoluzzo, A. B. (2022). Financiamento de longo prazo: Explorando o avanço recente do mercado de debêntures Brasileiro. Revista de Administração Contemporânea, 26(2), e210076. https://doi.org/10.1590/1982-7849rac2022210076.por
Classificação JEL: E.

Editores-chefes: Wesley Mendes-da-Silva (Fundação Getulio Vargas, EAESP, Brasil) (1) Marcelo de Souza Bispo (Universidade Federal da Paraíba, PPGA, Brasil) (1) Pareceristas: Michele Nascimento Jucá (Universidade Presbiteriana Mackenzie, CCSA, Brasil) (])
Hsia Hua Sheng (Fundação Getulio Vargas, EAESP, Brasil) (1] Relatório de Revisão por Pares: O Relatório de Revisão por Pares está disponivel neste link externo.

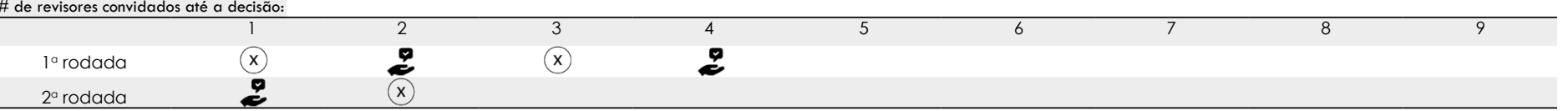




\section{INTRODUÇÃO}

Há um longo debate sobre como financiar projetos de infraestrutura. A literatura indica que tais projetos envolvem ativos de longo prazo e que requerem elevados volumes de captação (Ehlers, 2014). Países desenvolvidos contam com diversas formas de apoiar esses projetos, por meio de estruturas de captaçáo no âmbito privado, ainda que, dado o menor custo do capital público, também com recursos ou garantias estatais (Shaoul, 2005; Aghion, 1999). Porém, regióes com restrição de capital, como é o caso de países emergentes, apresentam uma série de restriçóes ao uso desses mecanismos. Riscos de credibilidade e baixa visibilidade sobre o retorno de investimentos acabam inibindo a atraçáo de capital privado, logo, limitando projetos de infraestrutura que poderiam gerar ganhos importantes de produtividade (Ehlers, 2014).

Dadas essas dificuldades, uma possibilidade que frequentemente se levanta é utilizar capital público para alavancar tais investimentos. Bancos públicos são frequentemente usados por governos para apoiar projetos com externalidades positivas, ou seja, com ganhos sociais, econômicos e ambientais gerados por esses investimentos (Aghion, 1999; Bruck, 1998). Contudo, a fragilidade institucional em países emergentes também gera custos da atuação estatal. Por exemplo, bancos estatais podem gerar má alocação de recursos públicos em projetos menos produtivos ou para empresas sem restriçóes de crédito aparentes, que poderiam se financiar no âmbito privado (Lazzarini, Musacchio, Bandeira-de-Mello, \& Marcon, 2015).

Nesse sentido, este trabalho busca lançar luz sobre esse debate avaliando a experiência brasileira recente de financiamento de infraestrutura no Brasil. Tradicionalmente, o Banco de Desenvolvimento Econômico e Social (BNDES), como agente público, teve papel relevante no apoio a projetos de infraestrutura (Bragança, Pessoa, \& Souza, 2015; Lazzarini et al., 2015; Lazzarini, Lima, \& Makhoul, 2017; Musacchio, Lazzarini, Makhoul, \& Simmons, 2017; Wajnberg, 2014). Porém, a partir de 2017, houve franca expansão de debêntures. Segundo dados da Associação Brasileira das Entidades dos Mercados Financeiro e de Capitais (Anbima), mais da metade das emissóes de debêntures realizadas entre 1995 e 2019 foi feita a partir de 2017. De fato, o Brasil já teve um mercado de debêntures com um tamanho que correspondia a $18 \%$ do produto interno bruto (PIB) do país nas primeiras décadas do século XX (Musacchio, 2009), superior ao patamar de 9\% atingido em 2019, segundo dados da Anbima e do Instituto Brasileiro de Geografia e Estatística (IBGE). Segundo Musacchio (2009), nesse período a legislação do país contava com diversos instrumentos de apoio aos credores, o que aumentava a segurança dos investidores para alocar seus recursos em debêntures.

Especificamente, o objetivo deste trabalho é analisar essa expansão recente de debêntures no Brasil e elencar seus possíveis fatores determinantes. Partindo dessa questão inicial, testou-se a hipótese de que houve uma mudança estrutural no mercado de debêntures brasileiro por meio de modelo estatístico de séries temporais. Em seguida, avaliouse, por meio de metodologia qualitativa (entrevistas), quais teriam sido os possíveis fatores que impulsionaram essa alteraçáo. Logo, o estudo adotou pesquisa mista, envolvendo dados quantitativos e qualitativos. Esse método se justifica pela complexidade do fenômeno estudado e pela importância de fatores contextuais, como mudanças em condiçóes regulatórias ou, de forma mais ampla, fatores institucionais (Sale, Lohfeld, \& Brazil, 2002).

A etapa quantitativa busca determinar quando ocorreu a mudança no comportamento do mercado de debêntures no Brasil, por meio do método econométrico de quebras estruturais. Esse tipo de teste é frequentemente utilizado em modelos baseados em séries temporais, mostrando mudanças de tendência e a existência de efeitos anormais nessas séries (Ferreira, Menezes, \& Oliveira, 2013). No caso desse estudo, utilizou-se uma base de dados disponibilizada pela Anbima, contendo informaçóes sobre emissóes de debêntures de 727 empresas entre 1989 e 2019. Já a etapa qualitativa buscou dar suporte empírico aos resultados quantitativos, por meio de uma análise exploratória de entrevistas com profissionais de tesouraria de emissores frequentes de debêntures. Entrevistas são recorrentemente utilizadas para buscar profundidade sobre o fenômeno explorado, além de ser uma forma de selecionar a fonte da informação perseguida (Stokes \& Bergin, 2006).

Os resultados quantitativos do estudo sugerem que, de fato, houve uma mudança de tendência nas emissóes de debêntures no mercado brasileiro a partir de 2017, tanto para o mercado como um todo quanto para os setores avaliados. Além disso, foi possível observar que alguns dos setores incluídos neste estudo tiveram um desempenho estatisticamente superior aos demais - notadamente, o setor elétrico, com um crescimento médio anual de $55 \%$ em suas emissóes a partir de 2011.

A análise qualitativa complementa os resultados anteriores por mostrar possíveis determinantes dessa evoluçáo. Segundo os participantes, a queda na taxa básica de juros do Brasil (Selic), associada a uma redução dos subsídios nas taxas praticadas pelo BNDES, poderia ter impulsionado as emissóes de debêntures por empresas brasileiras. Além disso, houve também um aumento na demanda por esses títulos em decorrência da queda dos juros no Brasil e da crescente experiência dos atores locais em utilizar fontes privadas de crédito. 
Dessa forma, no âmbito acadêmico, os resultados reforçam a importância de fatores ligados ao ambiente econômico e institucional afetando os custos de transação dos agentes econômicos e permitindo arranjos no contexto privado (Musacchio et al., 2017; Paula \& Faria, 2012). Porém, o estudo também indica que fatores em nível nacional são heterogêneos a partir de efeitos que ocorrem em nível setorial. Portanto, abre-se espaço para avanços em abordagens que integrem fatores institucionais com dinâmicas que ocorrem a partir de setores com demandas particulares de financiamento. No âmbito aplicado, o trabalho sugere que o mercado brasileiro de capitais poderia ser capaz de aplicar fontes de crédito privadas, caso políticas governamentais buscassem reduzir custos sistêmicos de capital e estimulassem o aprendizado local em novas formas de financiamento. Com isso, entidades estatais teriam mais espaço para focar seus esforços em empresas com restrição de crédito, deixando a cargo do mercado privado financiar companhias sem limitações de financiamento.

\section{LITERATURA: FINANCIAMENTO DE INFRAESTRUTURA E O PAPEL DAS FONTES PÚBLICAS E PRIVADAS}

Investimentos em infraestrutura possuem aspectos que dificultam seu financiamento. Questóes relacionadas a extensos prazos de maturação e incertezas em relação ao retorno desses investimentos complicam sua análise por parceiros privados (Ehlers, 2014). Além disso, em países emergentes os riscos políticos e judiciais seriam aspectos importantes na avaliação desses investimentos (Ehlers, 2014). Em complemento a essa visão, Alles (2001) explora as limitaçóes que os bancos privados possuem em emprestar recursos no longo prazo. Instituições financeiras são governadas por regulaçóes criadas para garantir liquidez aos depositantes, evitando exposiçóes excessivas a risco, o que ocorre em projetos de maturação tardia (Alles, 2001).

Por outro lado, países desenvolvidos, como é o caso do Reino Unido, criaram programas com foco no setor privado para financiar a modernização da infraestrutura do país, incluindo estradas, prisóes, hospitais e escolas na década de 90. Um argumento a favor dessa iniciativa, chamada de private finance initiative (PFI), era sua geração de valor em comparação com os recursos gastos nos projetos. Outro fator importante considerado na época era a transferência dos riscos financeiros para o setor privado, o que aparentemente seria positivo para os contribuintes (Shaoul, 2005).

Contudo, estudos sobre a intervenção estatal no sistema financeiro sugerem que sem a participação do governo, a falta de confiança entre credores e investidores impactaria o desenvolvimento do mercado de crédito (Gerschenkron, 1962). Como bancos comuns possuem limitações regulatórias de exposição ao risco, projetos de impacto poderiam ser deixados de lado, por conta dessas restriçóes (Alles, 2001; Bruck, 1998).

Uma forma de viabilizar a participação do capital público no apoio a projetos é o uso de bancos de desenvolvimento (Aghion, 1999). Segundo a autora, essas instituiçóes investem mais na expertise necessária para apoiar projetos de longo prazo do que bancos privados. Especificamente em países em desenvolvimento, Amsden (1992) aponta que bancos de desenvolvimento não somente eram importantes em apoiar projetos de longo prazo, mas também eram bons instrumentos de identificação e acompanhamento de projetos de investimento. Contudo, segundo Aghion (1999), existe uma percepção geral de que bancos de desenvolvimento de países em desenvolvimento falhariam com frequência em replicar modelos de sucesso. Altos índices de atraso, fracas avaliaçóes de custo-benefício e casos de corrupção associados à má gestão contribuíram para essa imagem negativa (Aghion, 1999).

Transportando o raciocínio para o contexto brasileiro, diversos autores indicam a dificuldade de se financiar projetos de longo prazo no Brasil (Armijo \& Rhodes, 2017; Bragança et al., 2015; Lazzarini et al., 2015; Machado, Martini, \& Gama, 2017; Torres \& Costa, 2012; Wajnberg, 2014). Uma das causas apontadas é a falta de capital privado de longo prazo (Alles, 2001; Ehlers, 2014; Maksimovic \& Demirgückunt, 2002). Entretanto, Musacchio (2009) sugere que o mercado de capitais de renda fixa já foi a principal fonte de capital para projetos no Brasil. O autor aponta que o mercado de bonds nacional (também conhecido como debêntures) teve papel importante no financiamento das empresas brasileiras após 1880, o que pode ser demonstrado pelo crescimento expressivo no volume de emissóes visto nesse período, quando esse mercado equivalia a $60 \%$ do tamanho da bolsa de valores do Rio de Janeiro (Musacchio, 2009).

Um ponto importante dessa discussão é entender quais teriam sido as condiçôes econômicas e regulatórias que suportaram esse mercado. Porta, Lopez-de-Silanes, Shleifer e Vishny (2014) definiram alguns fatores regulatórios importantes para o estabelecimento de um sistema financeiro sólido. Entre essas condiçóes destaca-se o direito de credores em recuperar garantias recebidas em caso de default, prioridade em processos de recuperação judicial e direito de nomeaçáo de executivos nas empresas devedoras (Porta, Lopez-de-Silanes, Shleifer, \& Vishny, 2014). Segundo Musacchio (2009), entre 1850 e 1945 a legislação brasileira contava com instrumentos relativamente fortes de proteção a credores, como, por exemplo, prioridade dos debenturistas em relação aos demais credores de uma empresa.

Contudo, ao longo das décadas que seguiram, o BNDES foi ganhando relevância no financiamento de 
grandes projetos, focando seus esforços em apoiar empresas estatais e privadas (Najberg, 1989). Por outro lado, Lazzarini, Musacchio, Bandeira-de-Mello e Marcon (2015) sugerem que não foi possível observar impacto positivo consistente no volume de investimentos e performance das empresas que captaram recursos com o BNDES no período avaliado. Nesse estudo, os autores acessaram dados de 286 empresas e usaram duas visões concorrentes, política industrial e partidária, como suporte para as hipóteses testadas. Segundo Bruck (1998), sob a ótica de política industrial, bancos de desenvolvimento podem exigir determinados padróes de performance na hora de emprestar recursos, com o objetivo de extrair os melhores resultados de um projeto.

Entretanto, ainda de acordo com Lazzarini et al. (2015) e Musacchio e Lazzarini (2015), seguindo a visão de política partidária, bancos de desenvolvimento podem se tornar instrumentos estatais de apoio a empresas em dificuldade ou, até mesmo, beneficiar politicamente empresas com boa relação com o governo. Tal fato pode implicar uma maior capacidade de empresas bem relacionadas com o governo adquirirem financiamentos dessas instituições públicas (Dinç, 2005).

Os resultados sugerem que as empresas que teriam a capacidade de acessar outras fontes de financiamento de longo prazo optavam por tomar recursos subsidiados com o BNDES, o que seria uma evidência de substituição de fontes de financiamento privadas pela pública (Lazzarini et al., 2015). Musacchio et al. (2017) exploram esse fenômeno de crowding out de intermediários privados por bancos de desenvolvimento. Segundo os autores, essas instituiçóes estariam reduzindo a atratividade do setor privado em financiar projetos, ao apoiar esses investimentos com taxas subsidiadas. Sob outra perspectiva, Ferraz e Coutinho (2019) argumentam que o BNDES tem seguido objetivos de desenvolvimento e que a maior parte dos recursos disponibilizados pelo banco foi direcionada a projetos buscando desenvolvimento da indústria e geração de empregos.

Vale notar que, em países emergentes, o mercado de capitais doméstico vem ganhando espaço como fonte de financiamento de corporaçóes. Abraham, Cortina e Schmukler (2021) demonstram que o mercado doméstico de bonds asiático cresceu de forma mais acentuada que o mercado internacional para empresas dessa regiáo entre 1990 e 2016 , com um aumento de $125 \%$ no número de emissores por ano na comparação entre os períodos 1990 1998 e 2008-2016, o que sugere a existência de alternativas ao financiamento bancário local.

De modo geral, fica claro que, independentemente da fonte do financiamento, um sistema financeiro desenvolvido tende a suportar o crescimento econômico de forma sustentável. $\mathrm{O}$ envolvimento do setor privado pode melhorar a execução e captação de recursos para projetos de infraestrutura. Já o papel do setor público, nesse caso, seria prover as condiçóes necessárias para que esse envolvimento do setor privado ocorra da melhor forma possível. Como investimentos em infraestrutura normalmente possuem extenso prazo de maturação, o risco de questóes políticas impactarem negativamente esses projetos aumenta. Credores e investidores teriam mais facilidade em prover recursos de longo prazo se eles pudessem confiar nos procedimentos legais e políticos das regiōes onde serão realizados os investimentos (Ehlers, 2014).

\section{CONTEXTO EMPÍRICO E MÉTODOS}

\section{Financiamento de infraestrutura no Brasil}

Historicamente, o Brasil tem investido aquém do desejável em projetos de infraestrutura (Lazzarini et al., 2017). Ainda que os desembolsos do BNDES com essa finalidade tenham saído de aproximadamente $\mathrm{R} \$ 15$ bilhóes, em 2005, para algo em torno de R $\$ 70$ bilhóes, em 2014, a taxa de investimento em relação ao PIB brasileiro é uma das mais baixas do mundo, sendo em média 10 p.p. abaixo da média mundial e 4 p.p. abaixo da dos países da América Latina e Caribe, segundo estimativas do Instituto Brasileiro de Economia da Fundação Getúlio Vargas (IBRE/FGV).

De fato, o Estado brasileiro teve papel relevante no apoio ao financiamento de projetos por meio do BNDES. Na primeira década de sua atuação, $69 \%$ das iniciativas apoiadas pelo banco eram associadas a projetos de infraestrutura, o que recentemente corresponde a $36 \%$. Porém, nas décadas que seguiram, o foco do banco mudou e o BNDES passou a financiar mais projetos ligados à indústria nacional. Mais recentemente, a partir de 2011, setores ligados ao comércio e a serviços ganharam espaço na carteira de financiamentos do banco (aproximadamente 24\%), principalmente por conta de projetos como o PSI (Programa de Sustentação do Investimento) e o Cartáo BNDES, segundo dados do relatório anual de performance do BNDES em Barboza, Furtado e Humberto (2018).

Um outro fator repetidamente discutido é o tamanho do BNDES em relação à economia brasileira. Barboza et al. (2018) apresentam essa evolução comparando o tamanho do banco com o PIB e a formação bruta de capital fixo (FBFC) do Brasil. Até 1999, a magnitude do BNDES em relaçáo ao PIB ficou abaixo de $1,0 \%$ na maior parte do tempo, valor que superou os 2,0\% a partir dos anos 2000 .

Outra forma de participação estatal no financiamento da economia é o encarteiramento de operaçôes de debêntures pelo BNDES. Historicamente, o BNDESPar (entidade de investimentos do BNDES) tem sido um participante ativo 
no mercado de debêntures. A posição de debêntures na carteira do banco, que já foi superior a $\mathrm{R} \$ 20$ bilhóes, perdeu relevância em relação ao mercado como um todo a partir 2005 , saindo de uma participação de $20 \%$ do mercado para $2 \%$ nos níveis atuais.

Todavia, a partir de 2017 é possível observar um avanço expressivo em emissóes de títulos de dívida privados (debêntures) no Brasil. Em 2011, foram criadas as chamadas debêntures incentivadas, com isençâo de Imposto de Renda para pessoa física, de acordo com a lei 12.431 (Bragança et al., 2015; Wajnberg, 2014). Segundo dados da Anbima, entre 2013 e 2018, as empresas emitiam em média 18 operaçóes de debêntures de infraestrutura, número que passou para 42 operaçóes em 2017 e para 65 em 2018. Porém, foi ao redor de 2017 que esses mecanismos tiveram um impulso substancial. Desde 1995, as empresas brasileiras emitiram mais de $\mathrm{R} \$ 700$ bilhóes em debêntures, sendo que mais da metade desse volume ocorreu somente a partir de 2017.

As debêntures lançadas nos últimos 20 anos estão concentradas em 10 setores, que foram responsáveis por mais de $90 \%$ dessas operaçóes. Excluindo o setor financeiro dessa análise, os segmentos de energia elétrica (14\%), transporte e logística (7\%) e comércio varejista (5\%) tiveram participação relevante nessas emissóes, contribuindo com quase $26 \%$ das operaçóes nesse período.

Conforme demonstrado na Figura 1, a partir de 2016, a maior parte dos setores avaliados teve um incremento em suas emissóes na comparação com 2011. Dentre esses segmentos, destaca-se o de energia elétrica, que apresentou um crescimento médio superior a 55\% ao ano.

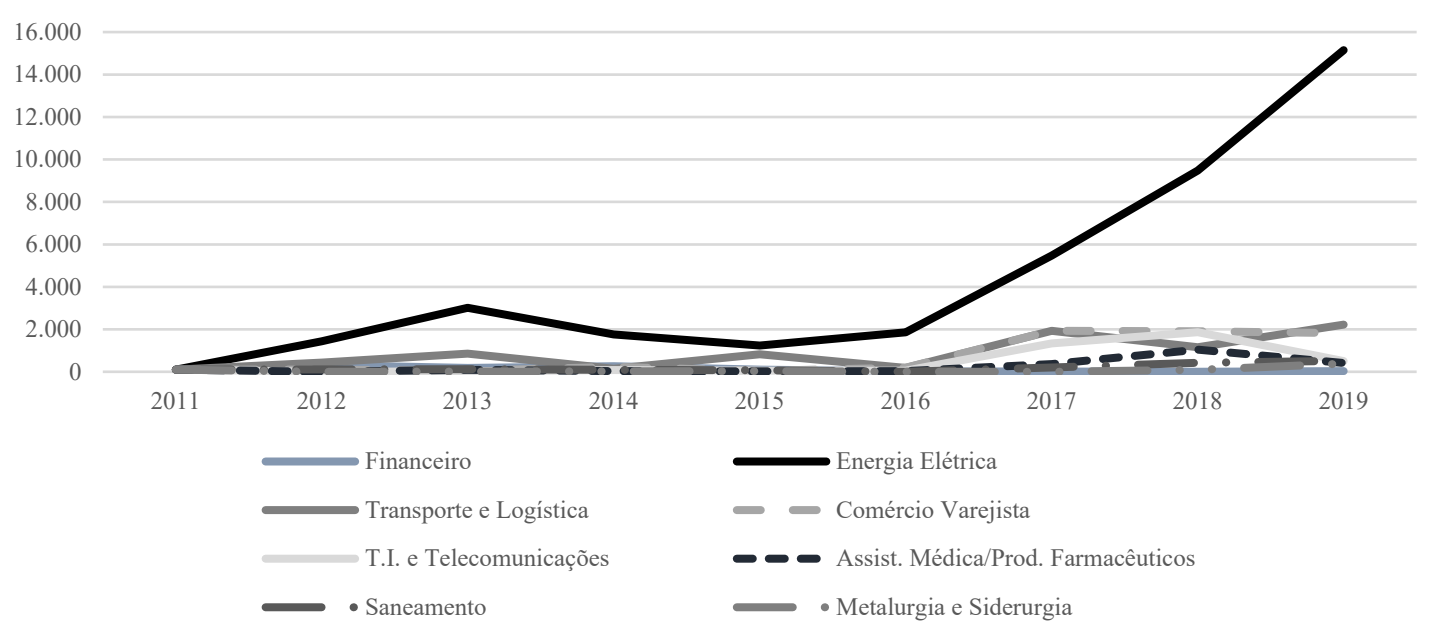

Figura 1. Evolução do volume de emissóes de debêntures por setor; base $100=2011$.

Fonte: Elaborado pelos autores baseado em dados da Anbima (https://www.anbima.com.br/pt br/pagina-inicial.htm recuperado em 15 de Dezembro, 2019)

Especificamente para debêntures de infraestrutura, esse instrumento vem ganhando relevância nos últimos anos, atingindo o mesmo patamar de desembolsos com infraestrutura do BNDES em setembro 2019, por volta de $\mathrm{R}$ \$ 17,4 bilhóes nos nove primeiros meses desse ano. Além disso, segundo o Ministério da Economia (2021), 56,8\% dos investimentos em infraestrutura do setor de energia elétrica foram financiados por debêntures, número que atingiu $44,2 \%$ no setor de transporte e logística e $60,6 \%$ no segmento de saneamento, segundo o Boletim Informativo de Debêntures Incentivadas - Janeiro 2020, que utilizou dados da Anbima e portarias ministeriais para compilar os dados de participação em projetos de infraestrutura.

Olhando para a demanda por esses instrumentos de dívida, dados da Anbima mostram que a partir de 2018 tanto o patrimônio líquido quanto o número de cotistas desses fundos cresceram de forma acentuada (acima de quatro vezes). Sendo assim, pode-se inferir que o crescimento da oferta desse tipo de título, conforme demonstrado anteriormente, também foi suportado por uma evolução na sua demanda. 


\section{Metodologia}

O comportamento visto no mercado de debêntures no Brasil é recente, sendo ainda muito pouco explorado no âmbito acadêmico. Além disso, o fenômeno envolve um conjunto complexo de questóes econômicas e institucionais, o que implica uma avaliação mais ampla dos fatores que o influenciam. Desse modo, optou-se por um método misto combinando etapas quantitativa e qualitativa.

Autores dentro do espectro das ciências sociais sugerem que metodologias quantitativas e qualitativas poderiam ser usadas de forma complementar e que essas estratégias não seriam excludentes (Webb, Campbell, Schwartz, \& Sechrest, 1966). Um dos argumentos mais usados a favor dos métodos mistos é a possibilidade de triangulação, ou seja, o uso de diferentes fontes de referência para abordar o mesmo fenômeno (Jick, 1979). Campbell e Fiske (1959) desenvolveram a ideia de que o uso de métodos mistos seria importante para a validaçáo dos resultados obtidos e que a convergência dessas metodologias seria uma fonte de robustez. Além disso, em determinadas áreas de estudo, metodologia mista é vista como uma forma interessante de explorar fenômenos complexos, que requerem informaçóes de diferentes fontes e perspectivas (Clarke \& Yaros, 1988).

Isto posto, como o estudo abordou um fenômeno ainda pouco investigado, explorar o contexto em que ele ocorre e quais são suas motivaçóes e particularidades requer o uso de metodologia qualitativa. Nesse caso, este estudo teve natureza exploratória, o que é adequado quando o objetivo é desenvolver proposiçóes relevantes, que poderão ser analisadas posteriormente. Além disso, as emissóes de debêntures e o financiamento em infraestrutura possuem vasta base de dados, o que possibilitou uma análise quantitativa do comportamento dessas variáveis. Dessa forma, este trabalho avaliou a evolução recente do mercado de debêntures por meio de dados públicos sobre essas emissóes, além de explorar quais seriam os fatores que colaboram para esse comportamento e, ainda, se existem aspectos setoriais específicos que o afetam.

\section{Etapa quantitativa}

A etapa quantitativa busca testar a hipótese de que houve uma quebra estrutural na evolução de emissóes de debêntures no Brasil recentemente. Para tanto, foram coletados dados da Anbima, englobando operaçóes entre 2011 e 2019. Durante esse período, 1.475 operaçóes estáo contempladas na base da Anbima, somando um volume de R\$ 576 bilhôes.

Nesse teste, utilizou-se a metodologia econométrica de quebras estruturais em séries temporais. Conforme apresentado em Zarei, Ariff, Hook e Nassir (2015), Ferreira,
Menezes e Oliveira (2013), Perron (2006) e Hansen (2001), esse tipo de metodologia possibilita a determinação de quando uma certa tendência mudou ao longo do tempo. $\mathrm{O}$ método usado neste estudo busca definir quebras estruturais em datas desconhecidas, conforme demonstrado em Jouini e Boutahar (2005), Andrews (1993) e Zivot e Andrews (1992), realizando múltiplos testes de Wald.

A estatística do teste de Wald é determinada pela equação (1):

$W_{T}=\frac{\left(\hat{\theta}-\theta_{0}\right)^{2}}{\left[I_{n}(\hat{\theta})\right]^{-1}}=I_{n}(\hat{\theta})\left[\hat{\theta}-\theta_{0}\right]^{2}$

sendo $\hat{\theta}$ o estimador de máxima verossimilhança (MLE); $\theta_{0}$ o valor assumido por $\hat{\theta}$ sob a hipótese nula $\left(\mathrm{H}_{0}\right) ; I_{n}(\hat{\theta})$ a informação esperada de Fisher. $\mathrm{O}$ teste segue a distribuição $\chi^{2}$ sob a hipótese nula $\left(\mathrm{H}_{0}\right)$.

Para a determinação de uma quebra estrutural, o teste de Wald verifica o quáo extrema é a amostra avaliada, ou seja, quanto maior a distância $\hat{\theta}-\theta_{0}$, maior será a probabilidade de se rejeitar a hipótese nula $\left(\mathrm{H}_{0}\right)$ de que no ponto testado não existe uma quebra estrutural.

No caso deste estudo, como o objetivo foi verificar se existe uma quebra estrutural dentro de uma série temporal, uma forma de operacionalizar esse procedimento foi realizar um teste de Wald para cada mês das séries históricas testadas. Esse conjunto de múltiplos testes de Wald é conhecido como teste de Wald Supremo e, assumindo $q$ como uma data de quebra dentro de um intervalo $\left[q_{1}, q_{2}\right]$, para uma amostra de tamanho $T$, a estatística do teste de Wald Supremo para testar a hipótese nula $\left(\mathrm{H}_{0}\right)$ de que não há quebra estrutural nos anos testados é dada por (2):

$S_{T}=\sup _{q_{1} \leq q \leq q_{2}} S_{T}(q)$

Uma segunda etapa dos testes quantitativos foi a determinação da intensidade da quebra estrutural setorialmente. Para tanto, utilizaram-se informaçóes dos segmentos que tiveram participaçáo relevante nas emissóes de debêntures no período em questão, ou seja, emissóes superiores a R \$ 10 bilhóes no período avaliado, sendo eles: financeiro, energia elétrica, transporte e logística, comércio varejista, TI e telecomunicaçóes, assistência médica/produtos farmacêuticos, saneamento e metalurgia/siderurgia.

Em seguida, realizou-se o teste de raiz unitária de Dickey-Fuller (ADF) para avaliar a estacionariedade das séries. Depois se estimou separadamente o efeito da quebra no volume mensal emitido de debêntures utilizando o logaritmo natural do volume emitido de debêntures para estabilizar a variância das séries de emissóes, incluindo 
as defasagens necessárias de acordo com a função de autocorrelação (FAC) de cada série, conforme (3):

$$
\ln \left(y_{i t}\right)=\alpha_{0 i}+\alpha_{1 i} \cdot \ln \left(y_{t-1 i}\right)+\alpha_{2 i} \cdot Q_{t i}+\varepsilon_{i t}
$$

sendo $\ln \left(y_{i t}\right)$ a variação percentual esperada do volume mensal de debêntures no i-ésimo setor avaliado, em função do mês da quebra e da variação percentual do volume mensal apurado no período imediatamente anterior; $Q_{t i}$ a variável dummy que assume valor zero para os meses anteriores à quebra estrutural e um para o mês de quebra e períodos posteriores; e $\varepsilon_{i t}$ o erro aleatório.

$\mathrm{Na}$ sequência, a fim de comparar o efeito setorial no volume total emitido pelo mercado de debêntures após a quebra, utilizou-se uma estimação em painel. Nesse caso, como o modelo em painel é dinâmico, a sua estimaçáa foi realizada usando o método de mínimos quadrados em dois estágios (2SLS). Assim, foram utilizados o volume apurado em $t-2$ e a variação entre os volumes em $t-1$ e $t-2$ como instrumentos, conforme demonstrado em (4):

$\ln \left(y_{i t}\right)=\beta_{0}+\beta_{i} \cdot \ln \left(y_{i t-1}\right)+\sum_{i=1}^{j-1} \delta_{i} \cdot Q_{t} \cdot S_{i}+\sum_{i=1}^{j-1} \gamma_{i} \cdot S_{i}+\varepsilon_{i t}$

sendo $\ln \left(y_{i t}\right)$ a variação percentual esperada do volume mensal total de debêntures em função do setor, do efeito temporal e do mês da quebra; $\delta i$ o parâmetro associado à interação entre a dummy da quebra estrutural $(Q)$ e as dummies setoriais $(S)$, que representa o efeito setorial na variação percentual do volume total mensal de debêntures depois da quebra estrutural, em relação a um setor de referência; $S_{i}$ as variáveis dummy que assumem valor um se o volume emitido for do setor em questáo; $i$ o indicador do setor; $j$ o número de setores avaliados; e $\varepsilon_{i t}$ o erro aleatório.

\section{Etapa qualitativa}

A fim de dar suporte aos resultados quantitativos deste estudo, entrevistas foram conduzidas com participantes do mercado financeiro brasileiro, buscando possíveis explicaçóes para essa quebra de tendência na emissão de debêntures no Brasil. Na sequência, o método de content analysis foi utilizado no processo de análise dos dados coletados nas entrevistas. Trata-se de uma metodologia própria para análise de comunicaçáo escrita e verbal, o que será importante na avaliação das entrevistas deste estudo (Elo \& Kyngäs, 2008).

O processo de entrevistas foi iniciado pela definição das perguntas, o que foi seguido pela criaçáo de um roteiro semiestruturado e, por fim, a escolha dos entrevistados. Segue a lista de questóes apresentadas aos participantes do estudo:
1. Como sua empresa financiava grandes projetos até 2017? Capital público (BNDES, por exemplo)? Mercado de capitais? Crédito privado?

2. Para você, quais são as fontes de financiamento mais atrativas neste momento?

3. Você acha que houve alguma mudança na forma como sua empresa financia grandes projetos a partir de 2017?

4. Quais fatores impulsionaram essa mudança, na sua visão (se houver)?

5. Na sua visão, a tendência atual de um alto nível de participação do mercado de capitais nas opçóes de financiamento de grandes projetos é sustentável?

6. Que mudanças estruturais seriam importantes para impulsionar ainda mais o mercado de debêntures nacional?

A primeira pergunta do questionário foi realizada com o objetivo de verificar se o Estado era uma importante fonte de financiamento dessas empresas. Conforme explorado em Machado et al. (2017), Musacchio et al. (2017), Lazzarini et al. (2015), Musacchio e Lazzarini (2015) e Machado, Grimaldi, Albuquerque e Santos (2014), o alto nível de participação do Estado no financiamento de corporaçôes é frequentemente questionado e, como os autores sugerem, em muitos casos não existe comprovação estatística de que esse apoio aumentou a intenção dessas empresas em investir em grandes projetos.

Em relação à segunda e à terceira pergunta, o principal objetivo era buscar evidências sobre como essas firmas estão se financiando neste momento. Um ponto importante desse questionamento é se realmente houve uma mudança no comportamento dessas empresas, passando a acessar o mercado de capitais na hora de financiar projetos de longo prazo.

A pergunta 4 serviu para complementar as duas questôes anteriores, além de confirmar o que foi previamente exposto na seção de contextualização e referencial literário. Conforme sugerido por Castro, Kalatzis e Martins-Filho (2015) e Ehlers (2014), o ambiente macroeconômico e a estrutura do sistema financeiro são importantes fatores que impactam o processo de decisão das empresas na hora de investir e de se financiar.

Na sequência, a questão 5 está associada à perenidade do momento vivido pelo mercado de debêntures a partir de 2017. Consoante ao que foi apresentado, o mercado de debêntures cresceu de forma relevante nos últimos três anos, sendo responsável por uma porçáo significativa dos financiamentos de projetos em setores importantes da economia nacional (Ministério da Economia, 2021). Isto posto, foi importante verificar se, na visão dos profissionais 
acessados, essa mudança de desempenho poderia ser duradoura.

Por fim, a última pergunta do questionário buscou indicaçóes sobre como o Estado poderia criar regras que facilitassem o acesso ao mercado de capitais, tanto por emissores como para investidores. Tal fato foi abordado por autores como Castro et al. (2015), Ehlers (2014), e Beck e Levine (2002), que exploraram medidas estatais que pudessem apoiar mais esse mercado.

$\mathrm{Na}$ sequência, buscaram-se informantes que pudessem apresentar relatos precisos e confiáveis sobre o assunto abordado (Cabral \& Krane, 2018). Para isso, foram entrevistados 10 profissionais que trabalham na área financeira de emissores de debêntures, com mais de 13 anos de experiência profissional em média, sendo quatro do setor de energia elétrica, quatro do setor de comércio varejista, um do setor de transporte e logística e um do setor de metalurgia e siderurgia.

Análises preliminares indicaram que os setores escolhidos tiveram uma participaçáo relevante no volume de emissóes de debêntures, mas com performances distintas. Além disso, os setores selecionados possuem diferentes necessidades de capital, o que permitiu examinar respostas heterogêneas sobre fatores que possam ter influenciado a evolução do mercado de debêntures. $O$ maior número de profissionais do setor elétrico e comércio varejista se deu pelo espectro amplo de empresas que sáo emissores frequentes na comparação com os demais segmentos avaliados.

Por fim, todas as conversas foram transcritas e analisadas usando o método de content analysis. Nessa etapa, seguindo o processo usado por Elo e Kyngäs (2008), White e Marsh (2006), Hsieh e Shannon (2005) e Stemler
(2001), foram definidas algumas ideias iniciais sobre temas que pudessem emergir das entrevistas, usando o referencial bibliográfico como base, em um processo dedutivo. Nesse tipo de abordagem, busca-se revisitar informaçóes já analisadas, sob um contexto diferente (Elo \& Kyngäs, 2008). Em seguida, as entrevistas foram analisadas, reconhecendo os temas definidos previamente e verificando a frequência com que eles apareciam e o seu contexto.

\section{RESULTADOS QUANTITATIVOS}

Os resultados sugerem que os conjuntos de dados avaliados são estacionários, com base no teste de raiz unitária ADF (Tabela 1). Em relação ao teste de quebra estrutural (Tabela 1), os resultados foram estatisticamente relevantes dentro de um intervalo de confiança de $95 \%$, exceto para o setor financeiro. Os testes sugerem que houve mudanças na tendência de emissóes de debêntures ao longo de 2017 no mercado em geral, exceto no segmento de metalurgia e siderurgia, que apresentou uma mudança de tendência estatisticamente significativa em agosto de 2018.

Como as séries temporais eram estacionárias, antes de se estimar o modelo de regressão, avaliou-se a existência de correlação entre o volume emitido de debêntures no passado e o volume no período avaliado com base no correlograma (FAC), apresentado na Tabela 1 . Os resultados sugerem que os setores de energia elétrica, transporte e logística, assistência médica e produção farmacêutica e o mercado em geral apresentaram a existência de correlação serial. Desse modo, para esses casos, a defasagem deve ser incluída nas regressóes.

Tabela 1. Teste ADF (raiz unitária), teste de quebras estruturais e FAC (correlograma) das séries temporais de emissão de debêntures.

\begin{tabular}{|c|c|c|c|c|c|}
\hline \multirow{2}{*}{ Setor } & \multicolumn{2}{|c|}{ Teste ADF } & \multicolumn{2}{|c|}{ Teste de Quebra Estrutural } & \multirow{2}{*}{$\begin{array}{c}\text { Teste FAC } \\
\text { (Correlograma) }\end{array}$} \\
\hline & N. ${ }^{\circ}$ de Observaçóes & Estatística do Teste & Data Estimada & Estatística do Teste & \\
\hline Financeiro & 107 & $-10,111^{* * *}$ & Fev./15 & $8,274^{*}$ & 0,020 \\
\hline Energia Elétrica & 107 & $-5,821^{* * *}$ & Set./17 & $47,470^{* * *}$ & $28,970^{* * *}$ \\
\hline Transporte e Logística & 107 & $-8,389^{* * *}$ & Jun./17 & $31,833^{* * *}$ & $4,301^{* *}$ \\
\hline Comércio Varejista & 107 & $-9,485^{* * *}$ & Abr./17 & $43,928^{* * *}$ & 0,658 \\
\hline TI e Telecomunicaçóes & 107 & $-9,371^{* * *}$ & Fev./17 & $15,962^{* * *}$ & 0,881 \\
\hline Ass. Médica/Prod. Farm. & 107 & $-7,762^{* * *}$ & Ago./17 & $40,682^{* * *}$ & $8,120^{* * *}$ \\
\hline Saneamento & 107 & $-8,701^{* * *}$ & Jul./17 & $15,381^{* * *}$ & $2,911^{*}$ \\
\hline Metalurgia e Siderurgia & 107 & $-9,017^{* * *}$ & Ago./18 & $22,856^{* * *}$ & 1,792 \\
\hline Mercado Total & 107 & $-6,431^{* * *}$ & Ago./17 & $65,746^{* * *}$ & $20,760^{* * *}$ \\
\hline
\end{tabular}

Nota. ${ }^{*}$ p-valor $<0,10{ }^{* *}$ p-valor $<0,05 ;{ }^{* * *}$ p-valor $<0,01$. 
Usando os resultados anteriores, esses efeitos na variação percentual do volume emitido de debêntures foram estimados (Tabela 2), em funçâo da data da quebra estrutural e da variação percentual do volume emitido de debêntures no período imediatamente anterior. Esse último parâmetro foi avaliado apenas para os setores determinados no teste FAC. Em relação ao efeito da mudança de tendência $\left(\beta_{2 i}\right)$, os resultados sugerem que todos os setores testados tiveram aumento nas emissóes de debêntures após a quebra estrutural com $95 \%$ de confiabilidade, exceto o segmento financeiro. Já para o efeito temporal na variação do volume mensal de debêntures $\left(\beta_{l i}\right)$, foi possível observar resultados estatisticamente significativos apenas para o mercado total de debêntures.

A partir da mudança de tendência em agosto de 2017, foi possível observar um aumento médio de $177 \%$ na emissão mensal de debêntures, tudo mais constante. Avaliando setor a setor, quatro segmentos de negócio tiverem um aumento médio em suas emissóes de debêntures superior a três vezes após a quebra estrutural: energia elétrica, transporte e logística, comércio varejista e assistência médica e produção farmacêutica. Os demais setores avaliados obtiveram incrementos estatisticamente relevantes entre $174 \%$ e $231 \%$ em média, tudo mais constante.

Tabela 2. Teste do efeito da quebra estrutural no volume mensal de emissóes por setor.

\begin{tabular}{|c|c|c|c|c|c|c|}
\hline Setor & $\begin{array}{l}\text { Data Estimada } \\
\text { (Mês/Ano) }\end{array}$ & N.o Observaçôes & F-Teste & $\beta_{0 i}$ & $\beta_{1 i}$ & $\beta_{2 i}$ \\
\hline \multicolumn{7}{|c|}{$\ln \left(y_{i t}\right)=\beta_{0 i}+\beta_{1 i} \cdot \ln \left(y_{t-1 i}\right)+\beta_{2 i} \cdot Q_{t i}+\varepsilon_{i t}$} \\
\hline \multirow{2}{*}{ Financeiro } & \multirow{2}{*}{ Fevereiro 2015} & \multirow{2}{*}{108} & \multirow{2}{*}{$3,17^{*}$} & $1,829^{* * *}$ & - & $-1,022^{*}$ \\
\hline & & & & $(0,425)$ & - & $(0,574)$ \\
\hline \multirow{2}{*}{ Energia Elétrica } & \multirow{2}{*}{ Setembro 2017} & \multirow{2}{*}{108} & \multirow{2}{*}{$16,39^{* * *}$} & $3,089^{* * *}$ & 0,081 & $3,142^{* * *}$ \\
\hline & & & & $(0,455)$ & $(0,098798)$ & $(0,686)$ \\
\hline \multirow{2}{*}{$\begin{array}{l}\text { Transporte e } \\
\text { Logística }\end{array}$} & \multirow{2}{*}{ Junho 2017} & \multirow{2}{*}{108} & \multirow{2}{*}{$11,67^{* * *}$} & $2,186^{* * *}$ & $-0,004$ & $3,014^{* * *}$ \\
\hline & & & & $(0,398)$ & $(0,097)$ & $(0,683)$ \\
\hline \multirow{2}{*}{ Comércio Varejista } & \multirow{2}{*}{ Abril 2017} & \multirow{2}{*}{108} & \multirow{2}{*}{$60,19^{* * *}$} & $1,075^{* * *}$ & - & $3,933^{* * *}$ \\
\hline & & & & $(0,280)$ & - & $(0,507)$ \\
\hline \multirow{2}{*}{$\begin{array}{l}\text { TI e } \\
\text { Telecomunicaçóes }\end{array}$} & \multirow{2}{*}{ Fevereiro 2017} & \multirow{2}{*}{108} & \multirow{2}{*}{$26,53^{* * *}$} & 0,410 & - & $2,309^{* * *}$ \\
\hline & & & & $(0,255)$ & - & $(0,448)$ \\
\hline \multirow{2}{*}{$\begin{array}{l}\text { Assist. Médica/ } \\
\text { Prod. Farm. }\end{array}$} & \multirow{2}{*}{ Agosto 2017} & \multirow{2}{*}{108} & \multirow{2}{*}{$24,30^{* * *}$} & $0,477^{*}$ & $-0,011$ & $3,240^{* * *}$ \\
\hline & & & & $(0,243)$ & $(0,098)$ & $(0,556)$ \\
\hline \multirow{2}{*}{ Saneamento } & \multirow{2}{*}{ Julho 2017} & \multirow{2}{*}{108} & \multirow{2}{*}{$15,14^{* * *}$} & $0,927^{* * *}$ & - & $1,957^{* * *}$ \\
\hline & & & & $(0,265)$ & - & $(0,503)$ \\
\hline \multirow{2}{*}{$\begin{array}{l}\text { Metalurgia e } \\
\text { Siderurgia }\end{array}$} & \multirow{2}{*}{ Agosto 2018} & \multirow{2}{*}{108} & \multirow{2}{*}{$11,93^{* * *}$} & $0,416^{* *}$ & - & $1,741^{* * *}$ \\
\hline & & & & $(0,200)$ & - & $(0,504)$ \\
\hline \multirow{2}{*}{ Mercado Total } & \multirow{2}{*}{ Agosto 2017} & \multirow{2}{*}{108} & $1007 * * *$ & $4,821^{* * *}$ & $0,276^{* * *}$ & $1,768^{* * *}$ \\
\hline & & & 19,01 & $(0,678)$ & $(0,096)$ & $(0,522)$ \\
\hline
\end{tabular}

Nota. Erro-padrăo robusto entre parênteses; ${ }^{*} \mathrm{p}$-valor $<0,10{ }^{* *} \mathrm{p}$-valor $<0,05$; $^{* *} \mathrm{p}$-valor $<0,01$.

O teste em painel dinâmico da Tabela 3 foi utilizado para avaliar dois parâmetros: (a) o efeito setorial na variaçáo percentual do volume emitido de debêntures depois da quebra estrutural, representado pelo parâmetro $\delta_{i}$; (b) o efeito setorial fixo na variação percentual do volume total emitido de debêntures pelos setores avaliados, representado pelo parâmetro $\gamma_{i}$. Esses dois parâmetros foram analisados em relação ao setor de metalurgia e siderurgia, que não foi incluído na regressão. Além disso, o efeito temporal na variação percentual do volume mensal de debêntures $\left(\beta_{1 i}\right)$ também foi incluído nessa avaliação. $\mathrm{O}$ teste de Hausman indicou a necessidade de trabalhar com efeitos fixos por causa da endogeneidade. O teste de Sargan demonstra que os instrumentos são exógenos com $5 \%$ de significância (valor-p $=0,561$ ), enquanto os testes de correlação serial demonstram existência de correlação serial de ordem 1 (AR1 - valor-p $=0,014)$ e ausência de correlação serial de ordem 2 (AR2 - valor- $\mathrm{p}=0,477)$, como era esperado. 
Foi feito o teste de White e detectou-se heterocedasticidade dos erros, então foram utilizados errospadrão robustos nos modelos. A normalidade dos erros foi rejeitada com base no teste Jarque-Bera, mas a amostra é considerada grande o suficiente para que os resultados sejam robustos a essa falta de normalidade, uma vez que o modelo de regressão tem 108 observaçooses para duas variáveis explicativas (de acordo com Heij, Boer, Franses, Kloek e Dijk (2004), o modelo deve ter pelo menos 10 observaçóes para cada variável explicativa).

Em relação a $\delta$, o teste sugere que apenas o setor de energia elétrica apresentou um resultado estatisticamente significativo. Após a quebra estrutural desse ramo de negócio, o volume total de debêntures exibiu um aumento de $63,70 \%$, em média (em relação ao setor de referência no período anterior à quebra), tudo mais constante.

Em relação ao efeito fixo setorial, apenas o setor financeiro não apresentou um resultado estatisticamente significativo com $95 \%$ de confiabilidade. Por fim, foi possível observar um resultado estatisticamente significativo para o efeito temporal na variação percentual do volume emitido de debêntures. Nesse caso, verificou-se uma influência igual a $12,76 \%$ de aumento no volume mensal total, em média, tudo mais constante.

Tabela 3. Teste em painel do efeito setorial no volume de emissóes mensal após a quebra estrutural e efeitos setoriais fixos.

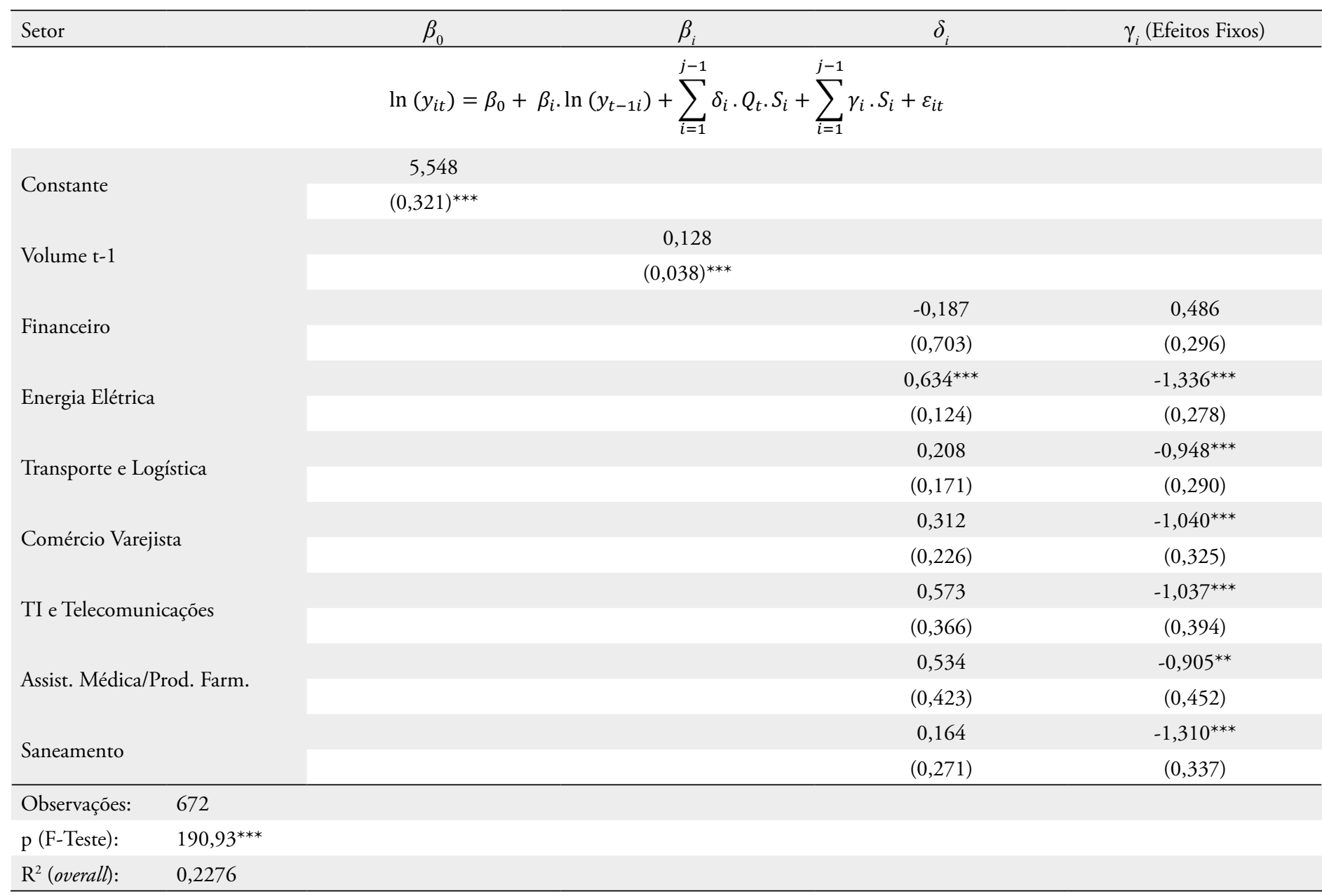

Nota. Erro-padráo robusto entre parênteses; ${ }^{*} \mathrm{p}$-valor $<0,10$; ${ }^{* *} \mathrm{p}$-valor $<0,05$; ${ }^{* *}$ p-valor $<0,01$.

\section{RESULTADOS QUALITATIVOS}

$\mathrm{O}$ processo de content analysis permitiu agrupar os achados de acordo com blocos de temas representando fatores relevantes para o fenômeno sob análise. Conforme demonstrado anteriormente, o financiamento de longo prazo no contexto nacional é regido por diversos aspectos, que vão desde questóes relacionadas à estrutura do sistema financeiro brasileiro (Castro, Kalatzis e Martins-Filho, 2015; Beck \& Levine, 2002) até o contexto macroeconômico vivido pelo país no momento analisado (Paula \& Faria, 2012). 
Logo, definiram-se os seguintes blocos de fatores emergindo das entrevistas e que podem explicar a evolução no mercado de debêntures e suas variações setoriais: (a) redução na participação estatal; (b) aumento na demanda por debêntures; (c) estrutura do sistema financeiro; (d) queda nas taxas de juros no Brasil; (e) impacto negativo de questóes regulatórias; (f) impacto negativo da burocracia. A Tabela 4 lista esses fatores e seus mecanismos envolvidos e inclui ilustraçóes de citaçóes das entrevistas.

Tabela 4. Resultados qualitativos.

\begin{tabular}{|c|c|c|}
\hline Possíveis fatores & Mecanismo envolvido & Citação ilustrativa de entrevistas \\
\hline Redução na participaçáo estatal & $\begin{array}{l}\text { Perda de competitividade das } \\
\text { fontes públicas (notadamente, } \\
\text { BNDES) por conta de maiores } \\
\text { custos financeiros relativos e } \\
\text { necessidade de garantias }\end{array}$ & $\begin{array}{l}\text { "Houve uma maior migração dessas operaçóes de prazo mais longo para o } \\
\text { mercado de capitais... Anteriormente havia muita participação do BNDES } \\
\text { nessas operaçóes de dívida... Na minha visão, isso foi se reduzindo à medida } \\
\text { que o BNDES começou a praticar taxas mais próximas às taxas de mercado, } \\
\text { reduzindo os subsídios que o banco costumava repassar. Nesse momento o } \\
\text { mercado de capitais começou a ganhar mais relevância por conta dos prazos } \\
\text { dessas operaçóes..." - Entrevistado do setor de metalurgia e siderurgia. }\end{array}$ \\
\hline $\begin{array}{c}\text { Aumento na demanda por } \\
\text { debêntures }\end{array}$ & $\begin{array}{l}\text { Um excesso de liquidez na mão } \\
\text { dos investidores aumentou a } \\
\text { procura por títulos corporativos, } \\
\text { como uma alternativa de alocaçáo } \\
\text { de capital }\end{array}$ & $\begin{array}{c}\text { "Entendo que o excesso de liquidez na mão dos investidores aumentou a } \\
\text { demanda por títulos corporativos, o que impactou o volume de operaçóes no } \\
\text { mercado." - Entrevistado do setor de metalurgia e siderurgia. }\end{array}$ \\
\hline Estrutura do sistema financeiro & $\begin{array}{l}\text { Limitaçóes do crédito bancário } \\
\text { para operaçóes de longo prazo }\end{array}$ & $\begin{array}{l}\text { "Em relação às debêntures, normalmente a empresa foca seus esforços em } \\
\text { operaçóes ICVM } 476 \ldots \text { Debêntures ainda sáo as fontes mais atrativas neste } \\
\text { momento... Um primeiro motivo é a questão do IOF. Como operaçóes } \\
\text { de mercado de capitais não possuem esse imposto, elas acabam sendo mais } \\
\text { competitivas do ponto de vista das operaçóes bancárias." - Entrevistado (2) do } \\
\text { setor de comércio varejista. }\end{array}$ \\
\hline Queda nas taxas de juros no Brasil & $\begin{array}{l}\text { Mudança de governo e perda } \\
\text { de competitividade da TJLP em } \\
\text { relaçáo à Selic }\end{array}$ & $\begin{array}{l}\text { "Houve uma mudança a partir do impeachment da presidente Dilma, quando as } \\
\text { empresas começaram a acessar mais o mercado de capitais nacional. O principal } \\
\text { motivo para isso é a queda nas taxas de juros, que tornaram as operaçóes do } \\
\text { BNDES caras relativamente." - Entrevistado (1) do setor de energia elétrica. }\end{array}$ \\
\hline $\begin{array}{l}\text { Impacto negativo de questôes } \\
\text { regulatórias }\end{array}$ & $\begin{array}{l}\text { Regulação reduz atratividade } \\
\text { de operaçóes incentivadas pelos } \\
\text { emissores }\end{array}$ & $\begin{array}{l}\text { "Para emissóes incentivadas, empresas tendem a ter um certo receio por conta } \\
\text { das incertezas relacionadas ao IR, principalmente para os títulos que usam } \\
\text { algum tipo de recebível como lastro, como CRA e CRI... Não fica claro se o } \\
\text { benefício é da securitizadora ou do emissor da debênture, o que aumenta o risco } \\
\text { de autuaçáo pela receita." - Entrevistado (3) do setor de comércio varejista. }\end{array}$ \\
\hline Impacto negativo da burocracia & $\begin{array}{l}\text { Os processos burocráticos de } \\
\text { registro de operaçóes no mercado } \\
\text { de capitais acabam atrasando a } \\
\text { emissão desses títulos, o que pode } \\
\text { aumentar o risco dessas transaçóes }\end{array}$ & $\begin{array}{l}\text { "O principal ponto de melhoria está associado a questóes burocráticas } \\
\text { judiciais, como registro em cartórios. A CVM já é bem atuante nesse mercado } \\
\text { de debêntures e já criou regulaçóes interessantes que reduzem os processos } \\
\text { de emissão de debêntures. Porém, os cartórios seriam os grandes gargalos de } \\
\text { temporais dessas operaçóes." - Entrevistado (4) do setor de energia elétrica. }\end{array}$ \\
\hline
\end{tabular}

\section{Redução na participação estatal}

De modo geral, as entrevistas sugerem que a participação estatal foi um fator importante nos financiamentos de empresas nos últimos anos. Por mais que boa parte dos entrevistados tenha mencionado que o BNDES não seria a fonte de recursos mais competitiva neste momento, o banco foi um dos principais financiadores dos setores avaliados até 2017 .

Segundo os entrevistados, com a criação da TLP, que buscou alinhar progressivamente as taxas do banco com aquelas praticadas pelo mercado, os custos do BNDES, que antes eram subsidiados, perderam competitividade na comparação com o mercado. Além disso, financiamentos do banco exigem garantias reais, o que reduz ainda mais o apetite dessas companhias.

Nesse sentido, à medida que as operações de mercado de capitais e bancárias se tornaram mais competitivas em comparação com as linhas de financiamento do BNDES, associadas a uma queda nas taxas de juros do mercado, a preferência dessas empresas foi mudando. Esse fato pode ser suportado pelos dados apresentados pelo Ministério da Economia (2021), nos quais é possível observar uma queda na remuneração exigida pelo mercado por títulos 
corporativos de infraestrutura, saindo de IPCA $+7,60 \%$ a.a. em 2015 para IPCA + 4,70\% a.a. em 2019. Além disso, o prazo médio dessas operaçóes também aumentou, atingindo 13,3 anos em 2019.

\section{Aumento na demanda por debêntures}

Nove dos dez participantes mencionaram o aumento na demanda por debêntures como uma das principais razóes para o incremento nas emissóes de debêntures a partir de 2017. De acordo com os entrevistados, nos últimos três anos a liquidez no mercado cresceu muito, o que aumentou a demanda por títulos corporativos. Além disso, boa parte dos participantes disse que a expansão das plataformas de investimento para pessoa física pode ter impulsionado esse aumento na demanda.

Em linha com o exposto pelos entrevistados, de fato o volume captado por fundos de investimento cresceu muito nos últimos anos. Segundo dados da Anbima (Ministério da Economia, 2021), o número de cotistas de fundos de infraestrutura cresceu $550 \%$ entre fevereiro de 2018 e dezembro de 2019, saindo de 27.618 para 179.228. Além disso, o patrimônio líquido desses fundos aumentou em $344 \%$ nesse mesmo período, atingindo R \$ 16,9 bilhóes ao final de 2019.

Além disso, por mais que a baixa liquidez do mercado secundário tenha sido um tema explorado por alguns dos entrevistados, dados da Anbima mostram que o volume negociado de debêntures cresceu $174 \%$ entre 2017 e 2019.

\section{Estrutura do sistema financeiro}

Em relação à estrutura do sistema financeiro brasileiro, não houve uma indicaçáo clara sobre qual seria a melhor fonte de financiamento para as empresas avaliadas. Segundo os profissionais abordados, na maioria das vezes, eles avaliavam as oportunidades de financiamento caso a caso. Tal fato é suportado pelo que foi exposto por Beck e Levine (2002), em que os autores sugerem que as fontes de financiamento não teriam efeito no desenvolvimento das empresas.

Além disso, esses profissionais citaram a preferência por destinar o crédito bancário direto para operaçóes de curto prazo, evitando eventuais problemas de liquidez, corroborando a visão de Maksimovic e Demirgüc-Kunt (2002) de que operaçóes bancárias estariam mais associadas a prazos mais curtos.

\section{Queda nas taxas de juros no Brasil}

A perda de atratividade por operaçóes do BNDES está muito associada à relação entre a taxa básica de juros do Brasil (Selic) e a Taxa de Juros de Longo Prazo (TJLP), segundo os entrevistados. Como boa parte das operaçóes do BNDES usava a TJLP como sua taxa base, essas linhas de crédito perderam espaço no balanço dessas empresas, conforme exemplificado abaixo na Figura 2.

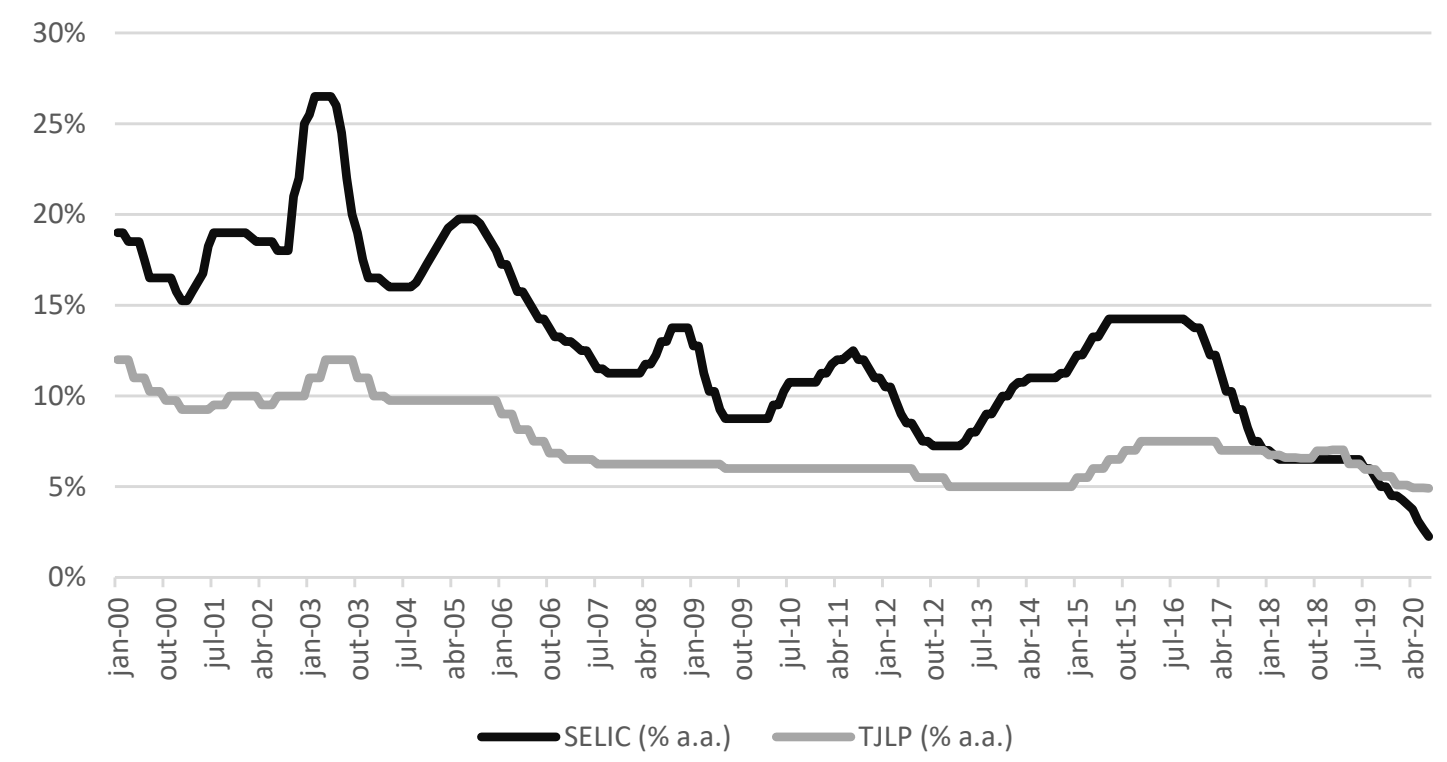

Figura 2. Evolução comparativa entre Selic e TJLP.

Fonte: Elaborado pelos autores baseado em dados da Bloomberg (https://www.bloomberg.com/ recuperado em 10 de Junho, 2020). 
Assim, ainda que o BNDES disponibilizasse estruturas de dívida específicas para projetos em alguns setores, o que pôde ser visto em Lazzarini et al. (2015), esses instrumentos se tornaram menos competitivos do ponto de vista de custo.

\section{Impacto negativo de questões regulatórias}

Os entrevistados abordaram algumas mudanças regulatórias que poderiam fomentar o mercado de debêntures. Primeiramente, os participantes relataram certa dificuldade no processo de enquadramento de suas operaçóes de debêntures como projetos de infraestrutura. Além disso, sem citar questóes específicas, os entrevistados mencionaram que seria importante a criação de regulaçóes que aumentassem a liquidez do mercado secundário de debêntures, em linha com o que foi explorado por Musacchio (2009).

Por fim, especificamente para operaçôes incentivadas, alguns profissionais demonstraram certa insegurança em relaçáo à tributação dessas operaçóes, o que segundo eles poderia ser mudado por meio de regras mais claras sobre esse aspecto.

\section{Impacto negativo da burocracia}

De acordo com os entrevistados, um dos fatores que freiam o mercado de debêntures é a burocracia. Segundo eles, os processos burocráticos de registro de operaçóes acabam atrasando a emissão desses títulos, o que pode aumentar o risco dessas transações.

Um exemplo seriam as emissões sob a regulação ICVM 400. Como esse tipo de operação mira investidores do tipo pessoa física, o processo de emissáo pode levar mais de três meses, o que muitas vezes incorre na necessidade de garantia firme dos bancos estruturadores da operação, impactando o custo dessas transaçóes.

Contudo, para empresas que são emissores frequentes, a burocracia parece não ser um problema. Um argumento apresentado pelos entrevistados é que essas empresas já possuem departamentos especializados nessas operações, o que facilita muito esse processo. Para esses profissionais, a burocracia teria um maior impacto em empresas menores.

\section{DISCUSSÃO}

Os resultados quantitativos deste estudo sugerem que, de fato, houve uma mudança de tendência nas emissóes de debêntures a partir de 2017, segundo os testes estatísticos de quebra estrutural. Estratificando essa análise para os principais setores emissores de debêntures, também foi possível verificar mudanças de tendência estatisticamente significativas ao longo de 2017 e 2018.

Outro ponto importante dessa análise foi avaliar se o comportamento das mudanças sofridas por cada segmento de negócio foi parecido. Nesse sentido, os resultados sugerem que alguns setores tiveram uma performance mais relevante do que os demais, como é o caso do setor de energia elétrica, sendo o único com efeitos estatisticamente significativos na performance do mercado como um todo após agosto de 2017.

De forma geral, a análise qualitativa sugere que o principal fator de mudança no comportamento do mercado de debêntures estaria associado à rápida queda nas taxas de juros vista a partir de 2017. Segundo boa parte dos entrevistados, esse fenômeno impactou a demanda por títulos de renda fixa, e também reduziu a discrepância entre o custo de instrumentos subsidiados do BNDES e as taxas praticadas pelo mercado como um todo.

Além disso, os resultados da análise qualitativa sugerem que, de fato, a participação estatal, por meio principalmente do BNDES, era um fator importante no financiamento das empresas avaliadas. Porém, o mercado de capitais se tornou um ator importante no apoio a projetos dessas empresas, substituindo, em algum nível, as entidades públicas. Segundo os entrevistados, essa mudança estaria apoiada principalmente no custo desses financiamentos. À medida que o BNDES se tornou menos competitivo em relaçáo às linhas privadas de crédito, essas empresas passaram a acessar o mercado privado na busca por financiamentos mais competitivos.

Dessa forma, existiriam dois grandes fatores que teriam mudado esse aspecto do mercado, a queda nas taxas de juros no Brasil e o crescimento do mercado secundário de debêntures. Segundo os entrevistados, com a queda da Selic, os investidores tiveram que realocar seus investimentos em operaçóes de maior risco, buscando uma maior rentabilidade. Nesse sentido, a procura por títulos corporativos aumentou muito, uma vez que esses instrumentos costumam remunerar mais os investidores, dado o seu maior nível de risco.

\section{CONSIDERAÇÕES FINAIS}

Um primeiro aspecto abordado sobre financiamento de longo prazo é a dificuldade de financiar projetos de longa maturação. Autores como Bruck (1998), Amsden (1992) e Gerschenkron (1962) abordaram a importância do Estado como uma fonte essencial de apoio a projetos de longo prazo. Este aspecto foi reforçado neste estudo, por meio do relato dos entrevistados, sugerindo que o estado teria sido uma importante fonte de financiamento nos últimos anos. 
Em segundo lugar, este estudo contribui para os trabalhos sobre qual seria a melhor estrutura do sistema financeiro para fomentar o crescimento econômico, como os de Khurana, Martin e Pereira (2006), Castro et al. (2015), Love (2003) e Beck e Levine (2002). Ficou evidente pelas entrevistas que independentemente da fonte de financiamento, as empresas avaliadas estão mais preocupadas com questóes relacionadas a custos e prazos de seus financiamentos.

Além disso, por mais que as companhias abordadas tivessem acesso a diversas fontes de financiamento, muitas delas optaram por usar linhas subsidiadas do BNDES, o que também foi explorado por Lazzarini et al. (2015). Tal constatação suporta a concepção de má alocação de recursos públicos direcionados ao financiamento de projetos e de crowding out de fontes privadas de recursos explorados pelo autor e por Musacchio et al. (2017). Ainda, conforme exemplificado por um dos entrevistados, o país tem hoje 13 mil empresas de médio porte sem nenhum tipo de financiamento de longo prazo. Logo, o apoio estatal pode ter efeito positivo para o desenvolvimento dessas empresas com restriçóes de capital (Lazzarini et al., 2015; Machado, Grimaldi, Albuquerque, \& Santos, 2014; Machado et al., 2017; Musacchio et al., 2017).

$\mathrm{O}$ acesso ao mercado de capitais por empresas pequenas e médias foi debatido por alguns dos entrevistados, principalmente em relação a questóes burocráticas e regulatórias queimpactariam essas entidades. Em consonância ao que foi explorado por Musacchio (2009) e Triner (2000), que abordaram a importância de um ambiente regulatório estruturado para o desenvolvimento do mercado de capitais, os entrevistados afirmaram que melhorias regulatórias e na burocracia seriam mais efetivas para empresas menores. Como operaçóes no mercado de capitais precisam de uma extensa documentação de suporte, segundo os entrevistados, empresas menores teriam dificuldade em cumprir com esses requisitos, por não contarem com uma estrutura interna desenvolvida, como é o caso das grandes empresas.

Todavia, ainda que a mudança vista no mercado de debêntures nos últimos anos pareça ser sustentável segundo os entrevistados, choques externos poderiam mudar essa perspectiva. Eventos que têm impacto severo na economia, como é o caso da pandemia de COVID-19, podem reduzir substancialmente a atratividade do mercado de capitais, reduzindo a precisão dos resultados deste estudo. Nesse sentido, a evolução vista nesse mercado pode não ser sustentável no curto prazo, sofrendo uma deterioração já em 2020. Um exemplo disso são os dados da Anbima divulgados em abril desse ano, que mostram impactos tanto da oferta quanto na demanda por títulos corporativos. Segundo relatório da Anbima, até abril de 2020 foram emitidos R \$ 7,1 bilhóes em debêntures. Nesse ritmo, o volume total para 2020 deverá ficar 36\% abaixo de 2019 . Além disso, o número de cotistas de fundos de investimentos em infraestrutura sofreu uma contração relevante em 2020, caindo mais de $30 \%$ nesse período.

Outro ponto também associado à crise de COVID-19 é o aumento da participação estatal na economia. Em momentos como esse, o Estado acaba servindo de base para a manutençâo da saúde financeira de empresas estratégicas à economia nacional. Um exemplo disso é a medida do BNDES em arcar com $20 \%$ a $25 \%$ dos empréstimos emergenciais para socorrer distribuidoras de energia elétrica. O que parece ser diferente nessa medida é o fato de o banco buscar o apoio de instituiçóes privadas, reduzindo o impacto em seu balanço. Esse apoio governamental estaria suportado na ideia de que o apoio estatal reduziria a desconfiança entre credores privados, que tende a ser mais intensa em momentos de escassez de crédito (Bruck, 1998; Gerschenkron, 1962). Nesse sentido, a redução da participação estatal por meio do BNDES, que pode ter sido um dos principais vetores de crescimento do mercado de capitais, deve voltar a aumentar em um primeiro momento.

Por fim, questóes associadas ao custo de emissóes no mercado de capitais deverão sofrer mudanças substanciais em um primeiro momento. Com o aumento do Risco-País, as emissóes de debêntures também devem ficar mais caras. Assim, a competitividade desses títulos em relação aos custos de operação com organismos estatais deverá cair, o que pode reduzir a intenção das empresas em emitir debêntures neste momento.

Isto posto, uma primeira sugestão para futuras pesquisas acerca desse tema seria abordar o nível de investimento das firmas nos setores avaliados após a crise vivida pelo país neste momento. Seria interessante observar se essas empresas mantiveram, pelo menos em parte, o seu nível de investimento em projetos, já que elas devem receber o apoio do Estado pelo que tudo indica. Outra possível abordagem sobre a evoluçáo do mercado de debêntures seria explorar o lado da demanda por esses títulos. Assim sendo, um estudo qualitativo sobre a perspectiva dos investidores em relação à evolução desse mercado a partir de 2017 poderia ampliar a concepção sobre esse fenômeno. 


\section{REFERÊNCIAS}

Abraham, F., Cortina, J. J., \& Schmukler, S. L. (2021). The rise of domestic capital markets for corporate financing: Lessons from East Asia. Journal of Banking and Finance, 122, 105987. https://doi.org/10.1016/j.jbankfin.2020.105987

Aghion, B. A. De (1999). Development banking. Journal of Development Economics, 58(1), 83-100. https://doi.org/10.1016/S0304-3878(98)00104-7

Alles, L. (2001). Asset securitization and structured financing: future prospects and challenges for emerging market countries. IMF Waking Paper, WP/02/6(October), 555-582.

Amsden, A. H. (1992). Asia's Next Giant: South Korea and Late Industrialization. USA: Oxford University Press. https://doi.org/10.1093/0195076036.001.0001

Andrews,D.W.K.(1993).Testsforparameterinstabilityandstructural change with unknown change point. Econometrica, 61(4), 821-856. http://www.jstor.org/stable/2951764

Armijo, L. E., \& Rhodes, S. D. (2017). Explaining infrastructure underperformance in Brazil: Cash, political institutions, corruption, and policy Gestalts. Policy Studies, 38(3), 231247. https://doi.org/10.1080/01442872.2017.1290227

Barboza, R. D. M., Furtado, M., \& Humberto, G. (2018). A atuação histórica do BNDES: O que os dados têm a nos dizer? Brazilian Journal of Political Economy, 39(3), 544560. https://doi.org/10.1590/0101-35172019-2910

Beck, T., \& Levine, R. (2002). Industry growth and capital allocation: Does having a market- or bank-based system matter? Journal of Financial Economics, 64(2), 147-180. https://doi.org/10.1016/S0304-405X(02)00074-0

Bragança, G., Pessoa, M., \& Souza, G. (2015). Evolução recente do mercado de debêntures no brasil: as debêntures incentivadas. Rio de Janeiro: IPEA, Texto para discussão 2158. https:// www.ipea.gov.br/portal/images/stories/PDFs/TDs/ td 2158.pdf

Bruck, N. (1998). The role of development banks in the twentyfirst century. Journal of Emerging Markets, 3(3), 39-67. Retrieved from https://www.adfiap.org/wp-content/ uploads/2009/10/the-role-of-development-banks-in-thetwenty-first-century.pdf

Cabral, S., \& Krane, D. (2018). Civic festivals and collaborative governance. International Review of Administrative Sciences, 84(1), 185-205. https://doi.org/10.1177/0020852315615196

Campbell, D. T., \& Fiske, D. W. (1959). Convergent and discriminant validation by the multitrait-multimethod matrix. Psychological Bulletin, 56(2), 81-105. https://doi.org/10.1037/h0046016

Castro, F., Kalatzis, A. E. G., \& Martins-Filho, C. (2015). Financing in an emerging economy: Does financial development or financial structure matter? Emerging Markets Review, 23, 96-123. https://doi.org/10.1016/j.ememar.2015.04.012
Clarke, A. P. N., \& Yaros, P. S. (1988). Research blenders: commentary and response: commentary: transitions to new methodologies in nursing sciences. Nursing Science Quarterly, 1(4), 147-149. https://doi.org/10.1177/089431848800100406

Dinç, I. S. (2005). Politicians and banks: Political influences on government-owned banks in emerging markets. Journal of Financial Economics, 77(2), 453-479. https://doi.org/10.1016/j.jfineco.2004.06.011

Ehlers, T. (2014). Understanding the challenges for infrastructure finance. BIS Working Papers, (454). Retrieved from https://www.bis.org/publ/work454.pdf

Elo, S., \& Kyngäs, H. (2008). The qualitative content analysis process. Journal of Advanced Nursing, 62(1), 107-115. https://doi.org/10.1111/j.1365-2648.2007.04569.x

Ferraz,J.C., \&Coutinho,L.(2019).Investmentpolicies, development finance and economic transformation: Lessons from BNDES. Structural Change and Economic Dynamics, 48, 86-102. https://doi.org/10.1016/j.strueco.2017.11.008

Ferreira, N., Menezes, R., \& Oliveira, M. M. (2013). Structural Breaks and Cointegration Analysis in the EU Developed Markets. International Journal of Finance, Insurance and Risk Management, 3(4), 652-661. https://doi.org/10.35808/ijfirm/86

Gerschenkron, A. (1962). Economic backwardness in historical perspective. Cambridge, MA: Harvard University Press. Retrieved from https:/www.hup.harvard.edu/catalog. php?isbn=9780674226005

Hansen, B. E. (2001). The new econometrics of structural change: Dating breaks in U.S. labour productivity. Journal of Economic Perspectives, 15(4), 117-128. https://doi.org/10.1257/jep.15.4.117

Heij, C., Boer, P., Franses, P. H., Kloek, T., \& Dijk, H. K. Van (2004). Econometric methods with applications in business and economics. New York: Oxford University Press.

Hsieh, H. F., \&Shannon, S. E. (2005). Three approaches to qualitative content analysis. Qualitative Health Research, 15(9), 12771288. https://doi.org/10.1177/1049732305276687

Jick, T. D. (1979). Mixing qualitative and quantitative methods: Triangulation in action. Administrative Science Quarterly, 24(4), 602-611. Retrieved from http://www.jstor.org/stable/2392366

Jouini, J., \& Boutahar, M. (2005). Evidence on structural changes in U.S. time series. Economic Modelling, 22(3), 391-422. https://doi.org/10.1016/j.econmod.2004.06.003

Khurana, I. K., Martin, X., \& Pereira, R. (2006). Financial development and the cash flow sensitivity of cash. Journal of Financial and Quantitative Analysis, 41(4), 787-807. Retrieved from https://www.jstor.org/stable/27647274

Lazzarini, S. G, Lima, T, \& Makhoul, P. (2017). Como aumentar a atraçáo de capital privado para financiar projetos de infraestrutura no Brasil. In A. C. Pastore (Org.). Infraestrutura: Eficiência e ética. São Paulo: Elsevier. 
Lazzarini, S. G., Musacchio, A., Bandeira-de-Mello, R., \& Marcon, R. (2015). What do state-owned development banks do? Evidence from BNDES, 2002-09. World Development, 66, 237-253. https://doi.org/10.1016/j.worlddev.2014.08.016

Love, I. (2003). Financial development and financing constraints: International evidence from the structural investment model. Review of Financial Studies, 16(3), 765-791. https://doi.org/10.1093/rfs/hhg013

Machado, L., Grimaldi, D. S., Albuquerque, B. E., \& Santos, L. O. (2014). Additionality of countercyclical credit: Evaluating the impact of BNDES' PSI on the investment of industrial firms. Rio de Janeiro: Banco Nacional de Desenvolvimento Econômico e Social. Retrieved from http://web.bndes.gov.br/bib/jspui/handle/1408/7758

Machado, L., Martini, R. A., \& Gama, M. M. da (2017). Does BNDES Innovation Credit Boost Firms' R\&D Expenditures? Evidence from Brazilian Panel Data. BNDES, [S.1. : s.n.], 1-17. Retrieved from http://web.bndes.gov.br/bib/jspui/handle/1408/13595

Maksimovic, V., \& Demirgüc-Kunt, A. (2002). Funding growth in bank-based and market-based financial systems: evidence fromfirm-leveldata. JournalofFinancialEconomics, 65,337363. https://doi.org/10.1016/S0304-405X(02)00145-9

Ministério da Economia. (2021). Boletim Informativo de Debêntures Incentivadas - Janeiro 2021. 86, 1-68. Retrieved from https://www.gov.br/economia/pt-br/ centrais-de-conteudo/publicacoes/boletins/boletimde-debentures-incentivadas/2021/spe-me-boletimdebentures-lei-12-431-jan-2021.pdf/view

Musacchio, A. (2009). Experiments in financial democracy: Corporate governance and financial development in Brazil, 1882 1950. Cambridge, MA: Cambridge University Press.

Musacchio, A., \& Lazzarini, S. G. (2015). Reinventando o capitalismo de Estado: O Leviatã nos negócios: Brasil e outros países. Sáo Paulo: Editora Schwarcz. Retrieved from https://www.companhiadasletras.com.br/detalhe/ trechos/75018.pdf

Musacchio, A., Lazzarini, S., Makhoul, P., \& Simmons, E. (2017). The role and impact of development banks a review of their founding, focus, and influence. November, 1-89. Retrieved from http://people.brandeis.edu/-aldom/ papers/The Role and Impact of Development Banks - 3-92017.pdf

Najberg, S. (1989). Privatização de recursos públicos: Os empréstimos do sistema BNDES ao setor privado nacional com correção monetária parcial (Dissertation). Pontifícia Universidade Católica, Rio de Janeiro, RJ, Brazil. Retrieved from http://web.bndes.gov.br/bib/jspui/handle/1408/15687

Paula, L. F. de, \& Faria, J. A. de (2012). Mercado de títulos de dívida corporativa privada no Brasil: Aspectos estruturais e evoluçáo recente. Revista de Economia Contemporanea, 16(1), 107-137. https://doi.org/10.1590/S1415-98482012000100006
Porta, R. La, Lopez-de-Silanes, F. Shleifer, A., \& Vishny, R. W. (1998). Law and finance. Journal of Political Economy, 106(6): 1113-1155. https://doi.org/10.1086/250042

Perron, P. (2006). Dealing with structural breaks. Palgrave Handbook of Econometrics, 1, 278-352. https://doi.org/10.1016/j.gf.2006.04.004

Sale, J. E. M., Lohfeld, L. H., \& Brazil, K. (2002). Revisiting the quantitative-qualitative debate: Implications for mixedmethods research. Quality and Quantity, 36(1), 43-53. https://doi.org/10.1023/A:1014301607592

Shaoul, J. (2005). A critical financial analysis of the private finance initiative: Selecting a financing method or allocating economic wealth? Critical Perspectives on Accounting, 16(4), 441-471. https://doi.org/10.1016/j.cpa.2003.06.001

Stemler, S. (2001). An overview of content analysis. Practical Assessment, Research and Evaluation, 7(17), 2000-2001. https://doi.org/10.7275/z6fm-2e34

Stokes, D., \& Bergin, R. (2006). Methodology or "methodolatry"? An evaluation of focus groups and depth interviews. Qualitative Market Research, 9(1), 26-37. https://doi.org/10.1108/13522750610640530

Torres, E. T. Filho, \& Costa, F. N. da. (2012). BNDES e o financiamento do desenvolvimento. Economia e Sociedade, 21(spe), 975-1009. https://doi.org/10.1590/s0104-06182012000400011

Triner, G. D. (2000). Banking and economic development: Brazil, 1889-1930. London, UK: Palgrave Macmillan.

Wajnberg, D. (2014). Debêntures de infraestrutura: emissóes realizadas e perspectivas. Revista do BNDES, 41, 331-378. Retrieved from https://www.bndes.gov.br/SiteBNDES/ export/sites/default/bndes_pt/Galerias/Arquivos/ conhecimento/revista/rev4108.pdf

Webb, E. J., Campbell, D. T., Schwartz, R. D., \& Sechrest, L. (1966). Unobtrusive measures: Nonreactive research in the social sciences. The Annals of the American Academy of Political and Social Science, 368(1), 229-230. https://doi.org/10.1177/000271626636800179

White, M. D., \& Marsh, E. E. (2006). Content analysis: A flexible methodology. Library Trends, 55(1), 22-45. https://doi.org/10.1353/lib.2006.0053

Zarei, A., Ariff, M., Hook, L. S., \& Nassir, A. M. (2015). Identifying multiple structural breaks in exchange rate series in a finance research. Pertanika Journal of Social Sciences and Humanities, 23, 155-166. Retrieved from https:// pureportal.coventry.ac.uk/en/publications/identifyingmultiple-structural-breaks-in-exchange-rate-series-in

Zivot, E., \& Andrews, D. W. K. (1992). Further evidence on the great crash, the oil-price shock, and the unit-root hypothesis. Journal of Business and Economic Statistics, 10(3), 251270. https://doi.org/10.1080/07350015.1992.10509904 


\section{Autoria}

\section{Lucas Boareto da Aparecida}

Instituto de Ensino e Pesquisa (INSPER)

R. Quatá, n. 300, Vila Olímpia, 04546-042, São Paulo, SP, Brasil

E-mail: lucasba1@al.insper.edu.br

(D) https://orcid.org/0000-0001-7257-6947

\section{Sergio Giovanetti Lazzarini}

Instituto de Ensino e Pesquisa (INSPER)

R. Quatá, n. 300, Vila Olímpia, 04546-042, São Paulo, SP, Brasil

E-mail: sergiogl1@insper.edu.br

(1) https://orcid.org/0000-0001-8191-1241

\section{Adriana Bruscato Bortoluzzo*}

Instituto de Ensino e Pesquisa (INSPER)

R. Quatá, n. 300, Vila Olímpia, 04546-042, São Paulo, SP, Brasil

E-mail: adrianab@insper.edu.br

(1) https://orcid.org/0000-0003-2872-031X

* Autora Correspondente

\section{Financiamento}

Os autores relataram que não houve suporte financeiro para pesquisa deste artigo.

\section{Conflito de Interesses}

Os autores informaram que não há conflito de interesses.

\section{Verificação de Plágio}

A RAC mantém a prática de submeter todos os documentos aprovados para publicação à verificação de plágio, mediante o emprego de ferramentas específicas, e.g.: iThenticate.

\section{Direitos Autorais}

A RAC detém os direitos autorais deste conteúdo.

\section{Método de Revisão por Pares}

Este conteúdo foi avaliado utilizando o processo de revisão por pares duplo-cego (double-blind peer-review). A divulgaçáo das informaçóes dos pareceristas constantes na primeira página e do Relatório de Revisão por Pares (Peer Review Report) é feita somente após a conclusão do processo avaliativo, e com o consentimento voluntário dos respectivos pareceristas e autores.

\section{Contribuições dos Autores}

$1^{a}$ autora: conceituaçáo (liderança); curadoria de dados (liderança); análise formal (igual); aquisição de financiamento (igual); investigação (igual); metodologia (igual); administração de projeto (igual); recursos (igual); software (igual); supervisão (igual); validação (igual); visualização (igual); escrita - rascunho original (igual); escrita - revisão e edição (igual).

$2^{\circ}$ autor: conceituação (igual); curadoria de dados (igual); análise formal (igual); aquisição de financiamento (igual); investigação (igual); metodologia (igual); administração de projeto (igual); recursos (igual); software (igual); supervisão (igual); validação (igual); visualização (igual); escrita rascunho original (igual); escrita - revisão e edição (igual).

$3^{a}$ autora: conceituação (suporte); curadoria de dados (suporte); análise formal (igual); aquisição de financiamento (igual); investigação (igual); metodologia (igual); administração de projeto (igual); recursos (igual); software (igual); supervisão (igual); validação (igual); visualização (igual); escrita - rascunho original (igual); escrita - revisão e ediçãoo (igual).

\section{Disponibilidade dos Dados}

Os autores afirmam que uma das bases utilizadas não permite a divulgação dos dados, mas que os demais dados foram divulgados por eles. Ainda, os autores afirmam que os códigos utilizados na pesquisa foram compartilhados. Os dados e códigos compartilhados pelos autores foram disponibilizados publicamente por meio da plataforma Harvard Dataverse e podem ser acessados em:

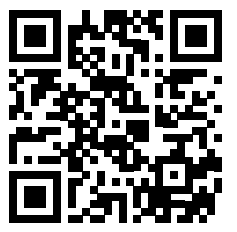

Aparecida, Lucas Boareto da; Lazzarini, Sergio Giovanetti; Bortoluzzo, Adriana Bruscato, 2021, "Replication Data for: Long term financing: exploring the recent development on the Brazilian bond market - published by RACRevista de Administraçáo Contemporânea", Harvard Dataverse, V1. https://doi.org/10.7910/DVN/ZWNO6O

A RAC incentiva o compartilhamento de dados mas, por observância a ditames éticos, não demanda a divulgação de qualquer meio de identificaçáo de sujeitos de pesquisa, preservando a privacidade dos sujeitos de pesquisa. A prática de open data é viabilizar a reproducibilidade de resultados, e assegurar a irrestrita transparência dos resultados da pesquisa publicada, sem que seja demandada a identidade de sujeitos de pesquisa. 


\section{APÊNDICE A.}

\section{Estatística descritiva}

A análise descritiva do volume emitido de debêntures no mercado nacional sugere que o setor de energia elétrica se destacou em relação ao número de operaçóes realizadas nos anos avaliados, com 265 emissóes (Tabela A1). No período analisado, $16,70 \%$ das debêntures emitidas vieram de empresas desse ramo de negócio. Além disso, excluindo o setor financeiro da análise, $18,70 \%$ dos recursos financeiros captados via debêntures foram para o setor de energia elétrica. Outro ponto demonstrado pela análise descritiva é que o volume médio por operação de debênture não variou muito nos segmentos de negócio avaliados. Apenas o setor financeiro apresentou operaçôes com valores individuais bem acima da média do mercado.

Tabela A1. Análise descritiva do volume emitido de debêntures nos setores avaliados.

\begin{tabular}{|c|c|c|c|c|}
\hline Setor & N. ${ }^{o}$ de Emissóes & $\begin{array}{l}\text { Volume Total } \\
\text { (R\$ milhóes) }\end{array}$ & $\begin{array}{c}\overline{\boldsymbol{X}} \text { Volume Médio } \\
\text { (R\$ milhóes) }\end{array}$ & $\begin{array}{c}\sigma \text { - Desvio-Padrão } \\
\text { (R\$ milhóes) }\end{array}$ \\
\hline Financeiro & 135 & 240.547 & 1.782 & 2.905 \\
\hline Energia Elétrica & 265 & 87.400 & 330 & 381 \\
\hline Transporte e Logística & 136 & 44.026 & 324 & 310 \\
\hline Comércio Varejista & 93 & 32.236 & 347 & 311 \\
\hline TI e Telecomunicaçôes & 32 & 16.199 & 506 & 806 \\
\hline Assist. Médica/Prod. Farm. & 30 & 13.653 & 455 & 397 \\
\hline Saneamento & 56 & 11.679 & 209 & 170 \\
\hline Metalurgia e Siderurgia & 14 & 10.682 & 763 & 641 \\
\hline Mercado Total & 1.585 & 707.539 & 446 & 1.060 \\
\hline
\end{tabular}

Nota. Fonte: Construção própria. 